\title{
The patient with rhinitis in the pharmacy. A cross-sectional study in real life
}

\author{
Carlo Lombardi ${ }^{1}$, Eleonora Musicco ${ }^{1}$, Francesco Rastrelli ${ }^{2}$, Germano Bettoncelli ${ }^{3}$, Giovanni Passalacqua ${ }^{4 *}$ \\ and Giorgio Walter Canonica ${ }^{4}$
}

\begin{abstract}
Background: In the practical management of allergic rhinitis (AR), pharmacists are usually the first-line contact, also because some medications are available as over the counter. Therefore, pharmacists may represent an important resource, in mediating the interaction between patients and physicians. We evaluated the clinical/ demographic characteristics of patients with respiratory allergies who consulted their pharmacists as first-line contact. A patient-oriented questionnaire was developed by a scientific committee including pharmacists, GPs, allergists, pulmonologists and ENT specialists.
\end{abstract}

Methods: The questionnaire consisted of items covering the general aspects of AR. Allergic Rhinitis and its Impact on Asthma guidelines were assumed as reference for diagnosis and therapy. The questionnaire was distributed to pharmacies, and pharmacists were asked to deliver the questionnaire to all patients referring for nasal symptoms.

Results: 30 pharmacies were involved during the pollen season 2011, and 410 patients (55\% male) participated. The most frequent complaints were 20 rhinitis (49\%) and conjunctivitis (29\%), followed by lower respiratory symptoms (cough and/or dyspnea). Isolated conjunctival symptoms were present in only $22 \%$ of patients. Among patients with lower respiratory symptoms, cough was the most frequent, variously associated with upper respiratory symptoms or overt dyspnea. Dyspnea alone was present in $16 \%$ of patients. $39 \%$ of patients had no physician-based diagnosis. Oral antihistamines were the most used self-medication, followed by intranasal decongestants. $30 \%$ of respondents had used alternative medicines.

Conclusion: According to these data, AR is still considered a trivial disease, frequently self-managed, with over the counter medications, not in line with guidelines. A physician-based diagnosis is present in about $60 \%$ of patients.

Keywords: Respiratory allergy, Allergic rhinitis, Allergic asthma, Pharmacist

\section{Background}

Respiratory allergic diseases (asthma/rhinitis) probably represent in absolute the most frequent immunemediated disorders [1], and their prevalence is still increasing worldwide, as recently underlined in the GEIRD (Gene Environment Interactions in Respiratory Diseases) epidemiological study [2]. The impact of respiratory allergy is of particular relevance when considering the costs, either direct (expenditure for drugs, hospitalizations, access to medical care) or indirect (absenteeism, presenteism, decreased school/

\footnotetext{
* Correspondence: passalacqua@unige.it

${ }^{4}$ Allergy \& Respiratory Diseases, Department of Internal Medicine, University of Genoa, Genoa, Italy

Full list of author information is available at the end of the article
}

work performance). Allergic Rhinitis (AR) is defined as a symptomatic disorder of the nasal mucosa, due to an IgE-mediated inflammation that follows the contact with an offending allergen. Cardinal symptoms of AR are nasal itching, sneezing, rhinorrhea and obstruction, and they are spontaneously reversible or controlled by adequate treatment [3-5]. AR can be frequently associated with other comorbidities, such as rhinosinusitis which is present in about $20-30 \%$ patients [6], asthma (10-35\%) [7], and conjunctivitis. Also polyposis and sleep disturbances [8,9], are not rare, occurring in not less than $10 \%$ of subjects. This aspects make the diagnostic approach sometimes particularly complex [10]. Nonetheless, AR is still considered as a "trivial" disease, that can be easily 
Table 1 Template of the questionnaire used

\begin{tabular}{|c|c|c|}
\hline & QUESTION & POSSIBLE ANSWERS \\
\hline \multirow[t]{2}{*}{1} & \multirow[t]{2}{*}{ Gender } & $\cdot M$ \\
\hline & & $\cdot F$ \\
\hline \multirow[t]{3}{*}{2} & \multirow[t]{4}{*}{ Age (years) } & $\cdot<20$ \\
\hline & & $\cdot 21-40$ \\
\hline & & $\cdot 41-60$ \\
\hline & & $\cdot>60$ \\
\hline \multirow[t]{3}{*}{3} & \multirow[t]{5}{*}{ Race } & - Caucasian \\
\hline & & - Asian \\
\hline & & - South American \\
\hline & & - Arab \\
\hline & & • Other............ \\
\hline \multirow[t]{4}{*}{4} & \multirow[t]{4}{*}{$\begin{array}{l}\text { Which symptom mainly } \\
\text { prompted you to go to } \\
\text { the pharmacy? }\end{array}$} & $\begin{array}{l}\text { - Rhinitis (sneezing, runny } \\
\text { nose, itchy nose, stuffy } \\
\text { nose) }\end{array}$ \\
\hline & & - Cough \\
\hline & & $\begin{array}{l}\text { - Conjunctivitis (burning } \\
\text { eyes, itchy eyes, } \\
\text { photophobia) }\end{array}$ \\
\hline & & - Dyspnea (short breath) \\
\hline \multirow[t]{4}{*}{5} & \multirow{4}{*}{$\begin{array}{l}\text { How long before your } \\
\text { visit to the pharmacy did } \\
\text { the symptom appear? }\end{array}$} & $\cdot<5$ days \\
\hline & & - 5-10 days \\
\hline & & - 11-30 days \\
\hline & & $\cdot>30$ days \\
\hline \multirow[t]{2}{*}{6} & \multirow{2}{*}{$\begin{array}{l}\text { The problem was already } \\
\text { diagnosed by a } \\
\text { physician? }\end{array}$} & - Yes \\
\hline & & - No \\
\hline \multirow[t]{2}{*}{7} & \multirow{2}{*}{$\begin{array}{l}\text { Did you received a } \\
\text { physician prescription for } \\
\text { your symptoms? }\end{array}$} & - Yes \\
\hline & & - No \\
\hline \multirow[t]{10}{*}{8} & \multirow{10}{*}{$\begin{array}{l}\text { Which medications do } \\
\text { you usually take?(multiple } \\
\text { answers allowed) }\end{array}$} & $\begin{array}{l}\text { - Topical nasal } \\
\text { decongestants }\end{array}$ \\
\hline & & - Systemic antihistamines \\
\hline & & - Topical antihistamines \\
\hline & & - Topical steroids \\
\hline & & - Systemic steroids \\
\hline & & - Topical anticholinergics \\
\hline & & - Topical Cromones \\
\hline & & - Antibiotics \\
\hline & & - Antileukotrienes \\
\hline & & $\begin{array}{l}\text { - If you can not specify } \\
\text { the class, indicate } \\
\text { commercial names }\end{array}$ \\
\hline \multirow[t]{2}{*}{9} & \multirow{2}{*}{$\begin{array}{l}\text { Do you use or have } \\
\text { used complementary/ } \\
\text { alternative medicines } \\
\text { (e.g. homeopathy, } \\
\text { acupuncture, herbs) for } \\
\text { your rhinitis/asthma? }\end{array}$} & - Yes \\
\hline & & - No \\
\hline
\end{tabular}

Table 1 Template of the questionnaire used (Continued)

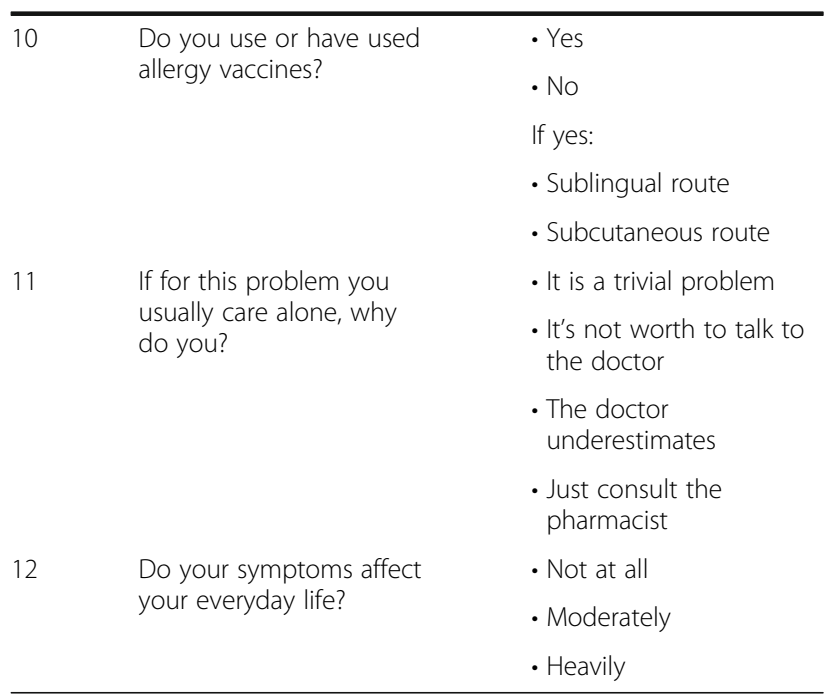

managed by the patient himself or by healthcare providers other than physicians. In this context, pharmacists are usually the first-line contact for AR patients $[3,11]$, also because, several medications (namely, oral/ local antihistamines and decongestants) are available as "over the counter" [12]. Therefore, pharmacists with an adequate preparation may represent an important healthcare resource, in mediating the contact between patients and physicians. This is especially true when a more detailed diagnostic approach is needed. Based on these considerations, we aimed at evaluating the clinical/demographic characteristics of patients suffering with respiratory allergies who consulted pharmacists as first-line contact. This was done by a questionnaire-based survey.

\section{Methods}

A patient-oriented questionnaire was developed by a scientific committee in which convened pharmacists (25\%), GPs (20\%), allergists (25\%), pulmunologists (15\%) and ENT (15\%) specialists. The questionnaire consisted of 12 items covering the main and general aspects of AR, as shown in Table 1. The questionnaire was discussed and agreed by the Provincial Board of Pharmacists of Brescia.

The Allergic Rhinitis and its Impact on Asthma (ARIA) document was assumed as guideline for diagnostic and therapeutic approaches $[3,10]$. The questionnaire, as a paper sheet, was distributed to pharmacies of the Brescia province and pharmacists were asked to deliver the questionnaire to all patients referring for nasal symptoms during the 2011 pollen season (February May). The participation into this survey was on a voluntary basis and all the personal/demographic data were kept strictly anonymous. The observational study 
was notified to the Conjunct Commission of Brescia Phisicians \& Pharmacists Orders, according to the Italian legislation.

\section{Results}

Thirty pharmacies, $54 \%$ in the urban area of Brescia and $46 \%$ in the surroundings, participated in this initiative. At the final collection, there were 410 respondent patients (55\% male, age range: $20-40$ years), all referring to pharmacies during the spring pollen season 2011 (February-May) for nasal/respiratory complaints (rhinitis, rhinosinusitis, asthma, conjunctivitis). Of note, the majority of subjects belonged to an age range characterized by active work/school/ sport activity. Out of the 410 patients, $19 \%$ were immigrants $(4 \%$ african, $3 \%$ arab, $3 \%$ asian, $2 \%$ latin american, $7 \%$ eastern european). This is in line to what previously observed in a cross-sectional study performed in this geographical area [13]. According to questionnaires, the most frequent complaints were rhinitis (49 \%) and conjunctivitis (29\%), followed by lower respiratory symptoms (cough and/or dyspnea) (Fig. 1). Rhinitis symptoms remained the main cause of spontaneous access to the pharmacy (320 patients out of 410 total, $76 \%$ of patients with rhinitis), responsible alone of $49 \%$ of consultations, and associated with conjunctivitis in $27 \%$ of the accesses (Fig. 2a). Isolated conjunctival symptoms did not appear as a relevant event, accounting for $29 \%$ of patients (Fig. 2b). Among patients with lower respiratory symptoms, cough was the preeminent reason for referral, and it was variously associated with upper respiratory symptoms or overt dyspnea (Fig. 2c). On the other hand, dyspnea alone was reported by $11 \%$ of patients (Fig. 2d). There was a wide time span between the onset of symptoms and the seek for care (Fig. 3), and in $39 \%$ of patients no physician-based diagnosis was declared, this underlining a high proportion of self-diagnosis and self-management. Notably, in $49 \%$ of immigrants, the problem had been not formally diagnosed, and $81 \%$ were not treated by a doctor. These patients were therefore underdiagnosed and undertreated. Even among immigrants, rhinitis was the disease that led patients to the attention of the pharmacist (Fig. 4). In general, Oral antihistamines (over the counter in Italy) were the most used self-medication drug, followed by intranasal decongestants (self medication in $22 \%$ of patients) (Fig. 5). Treatment options such as homeopathy or alternative medicine had already been used or actually used by $33 \%$ of the respondents. Concerning allergen-specific immunotherapy sublingual or subcutaneous, only $12 \%$ of the patients examined in our study had used it. The pharmacist resulted to be the first-line contact for $47 \%$ of patients, whereas $42 \%$ of the respondents considered its problem as trivial, and $11 \%$ reported that GPs under evaluated nasal symptoms. Finally, $28 \%$ of the respondents considered AR as heavily impacting on the quality of life and another 59 \% judged the impact as moderate.

\section{Discussion}

AR is a common and frequent healthcare problem, affecting almost $25 \%$ of the general population [1,2]. The epidemiological impact lead to the search for a better diagnostic definition and for an evidence-based approach to its therapy, as done with the ARIA guidelines [10], also considering that patients' profile is becoming more and more complex [14]. Nonetheless, AR still remains considered a trivial disease,

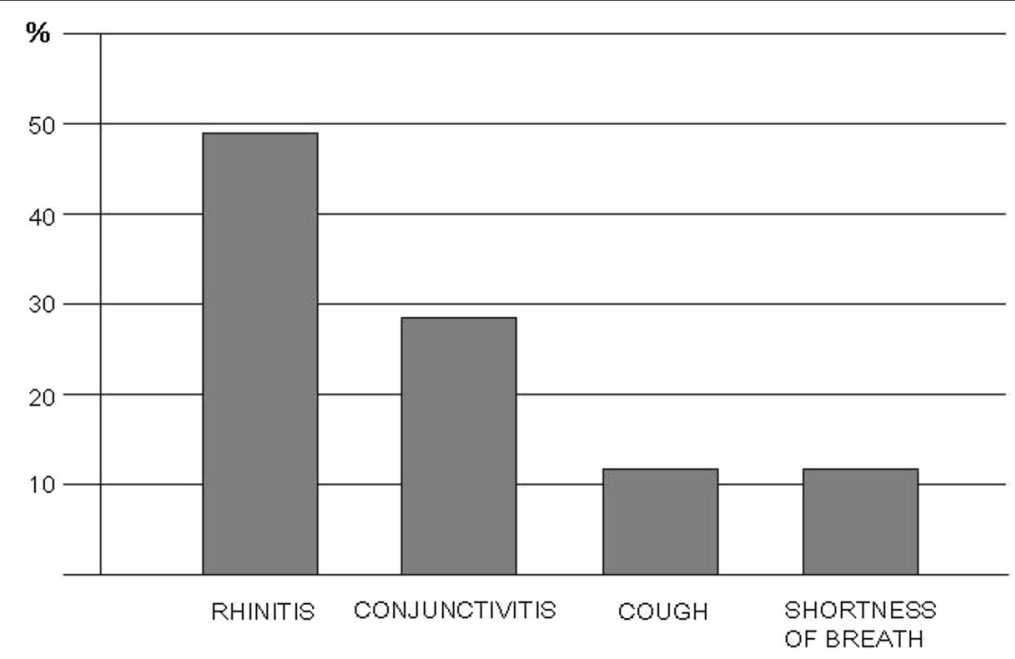

Fig. 1 Main Symptom reported by patients as reason for referral to pharmacy 
(A)

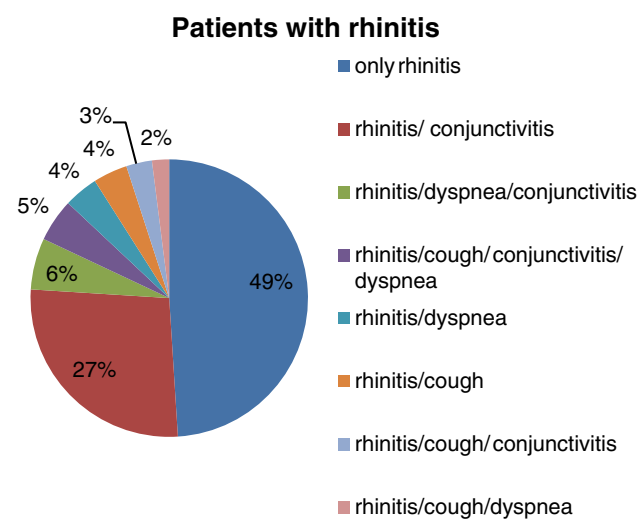

(C)

Patients with cough

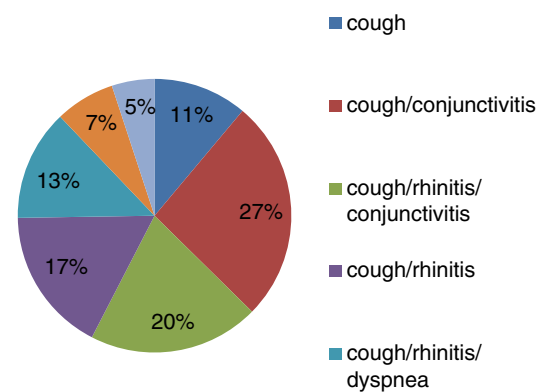

(B)

\section{Pazients with conjunctivitis}

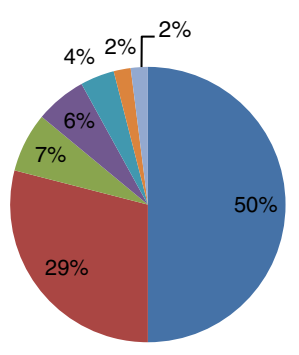

- rhinitis/conjunctivitis

- conjunctivitis

- conjunctivitis/

rhinitis/dyspnea

n conjunctivitis/rhinitis/

cough/dyspnea

- conjunctivitis/

rhinitis/cough

- conjunctivitis/cough

- conjunctivitis/dyspnea

(D)

\section{Pazients with dyspnea}

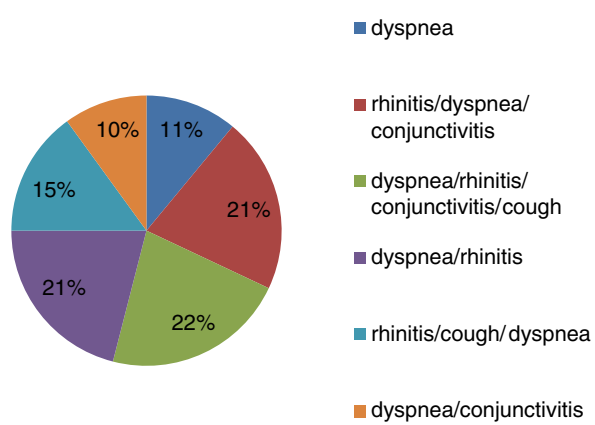

Fig. 2 The main symptom that leaded patients to pharmacies is confirmed to be rhinitis (a). Conjunctivitis (b), cough (c), and dyspnea (d), often associated with other allergic symptoms, in particular rhinitis

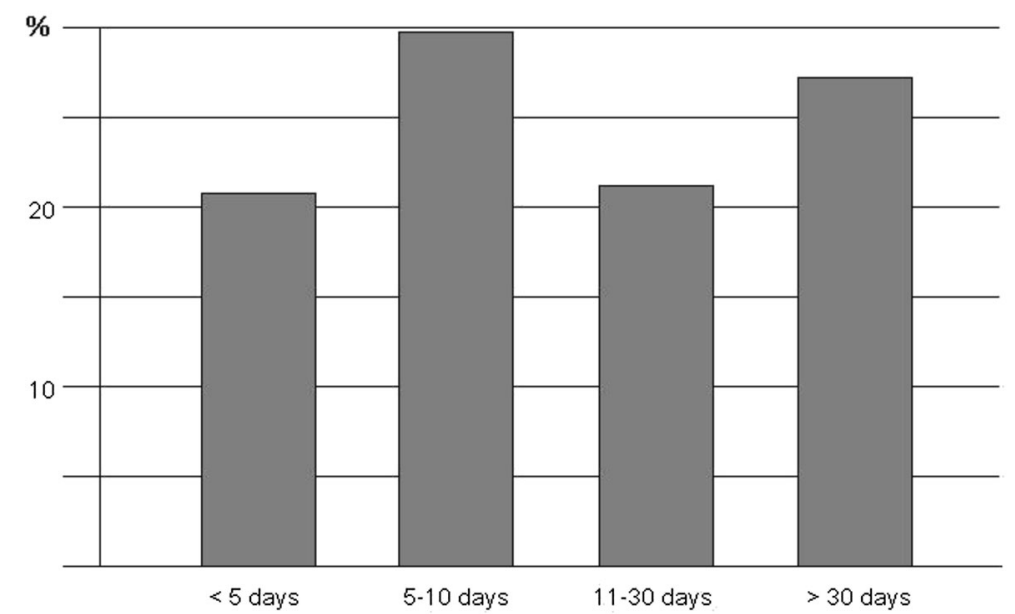

Fig. 3 Latency time between the onset of symptoms and the access to pharmacy. There is a wide distribution in the time period considered 


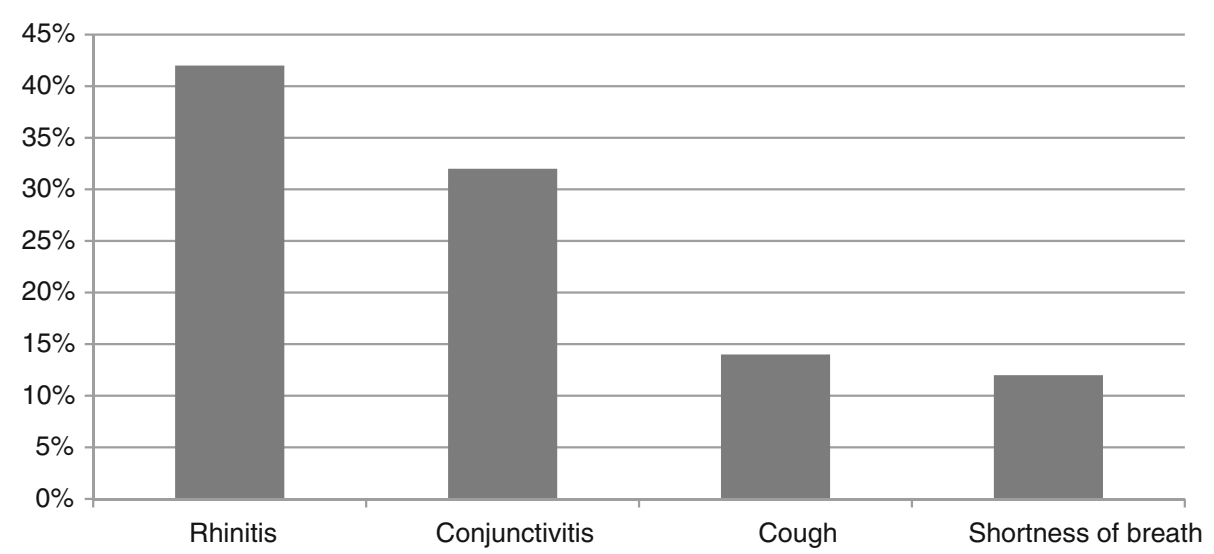

Fig. 4 Even among immigrant patients rhinitis remains the predominant allergic disease leading patients to the attention of the pharmacist

since it is not life-threatening and easy to manage [15]. For those reasons AR is frequently self-managed by patients, and the pharmacist, therefore, represent the first-line contact. Guidelines dedicated to pharmacists have been already published [4], but their real impact on everydays' practice have been not been specifically addressed so far. Thus, we attempted to evaluate the characteristics, diagnosis, treatment profile and perception of AR in a pharmacy setting. As expected, a vast majority of patients still retain the use of "over the counter" medicines as the primary resource, being rhinitis a self-manageable disease. Also, in line with the internationally increasing use of Complementary-Alternative Medicines [16], according to Italian data about one third of patients approached these therapies for their diseases or symptoms [17]. In general it is known that the reasons for the choice of the use of complementary medicines are multiple, among which prevails the conviction of the lower level of toxicity compared to conventional treatments [18].

\section{Conclusion}

According to our data, collected by pharmacists, a large percentage of patients still consider AR as a trivial disease [19], and recur to self-administered drugs (oral/nasal antihistamines and/or nasal vasoconstrictors), whereas an appropriate diagnosis is made only in few cases. In particular, the use of intranasal decongestants testifies for a nonoptimal management of AR, as well as the poor referral to physicians. This is in line with elsewhere reported data based on pharmacists' experience [20-22]. Finally, the use and knowledge of allergen-specific immunotherapy seems to need improvement. Based on the present results, a more strict and bi-directional collaboration between pharmacists and physicians would be auspicable.

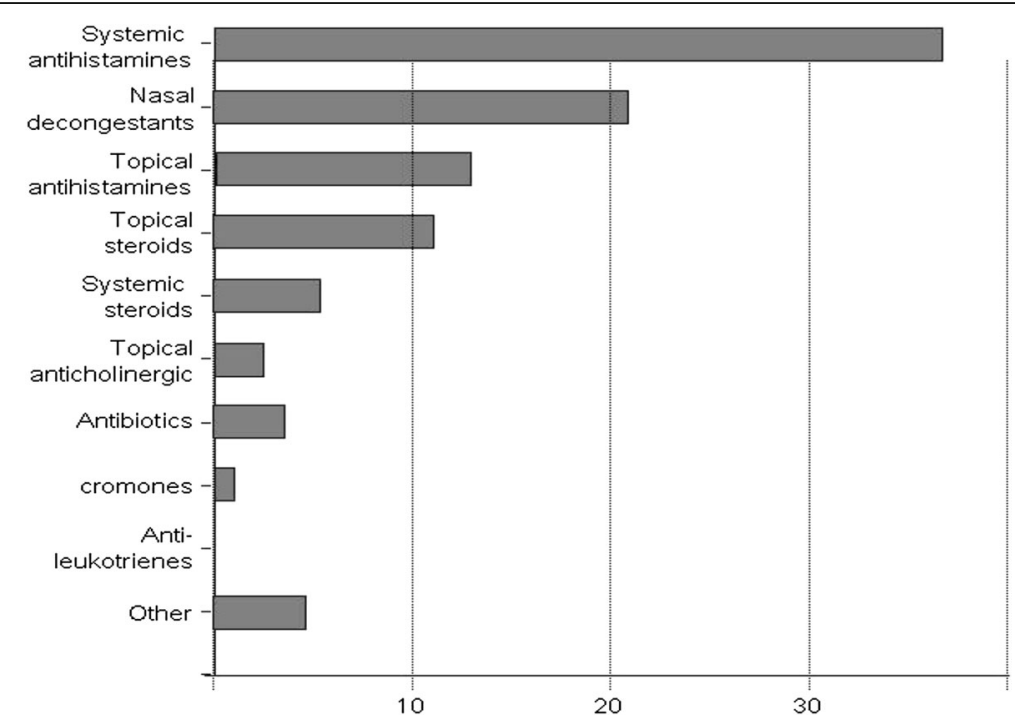

Fig. 5 Drug treatment mainly used/required by patients referred to the pharmacy for respiratory allergies. Antihistamines (36 \%) and topical nasal decongestants (21\%) predominate 


\section{Competing interests}

The authors declare that they have no competing interests.

\section{Authors' contributions}

Each author was responsible for the clinical work, collection and analysis of data and drafting the manuscript. All authors read and approved the final manuscript.

\section{Acknowledgements}

We are grateful to Nadia Marcobruni MD (Unit of Pneumology, Spedali Civil Hospital, Brescia, Italy) and Davide Tomenzoli MD (Unit of Otolaryngology, Spedali Civili Hospital, Brescia, Italy), who participated in the preliminary phase of the study.

\section{Author details}

${ }^{1}$ Unit of Allergy-Clinical Immunology \& Respiratory Diseases - Department of Medicine \& Geriatrics, Poliambulanza Hospital Institute, Brescia, Italy. ${ }^{2}$ President of the Order of Pharmacists of Brescia, Brescia, Italy. ${ }^{3}$ General Practitioner, Brescia, National Responsible for the Pulmonology Area of the Italian Society of General Practitioners (SIMMG), Brescia, Italy. ${ }^{4}$ Allergy \& Respiratory Diseases, Department of Internal Medicine, University of Genoa, Genoa, Italy.

\section{Received: 17 April 2014 Accepted: 5 May 2015}

Published online: 04 June 2015

\section{References}

1. Bousquet J, Van Cauwenberge P, Khaltaev N. Allergic rhinitis and its impact on asthma. J Allergy Clin Immunol. 2001;108(5 Suppl):S147-334.

2. De Marco R, Cappa V, Accordini S, Rava M, Antonicelli L, Bortolami O, et al. Trends in the prevalence of asthma and allergic rhinitis in Italy between 1991 and 2010. Eur Respir J. 2012;39:883-92.

3. Bousquet J, Van Cauwenberge P, Khaltaev N. ARIA in the pharmacy: management of allergic rhinitis symptoms in the pharmacy. Allergy. 2004;59:373-87.

4. International Consensus Report on Diagnosis and Management of Rhinitis. International Rhinitis Management Working Group. Allergy. 1994;49(19 Suppl):1-34.

5. van Cauwenberge P, Bachert C, Passalacqua G, Bousquet J, Canonica GW, Durham SR, et al. Consensus statement on the treatment of allergic rhinitis. European Academy of Allergology and Clinical Immunology. Allergy. 2000;55:116-34.

6. Georgalas C, Vlastos I, Picavet V, van Drunen C, Garas G. Prokopakis Is chronic rhinosinusitis related to allergic rhinitis in adults and children? Applying epidemiological guidelines for causation. Allergy. 2014;69:828-33.

7. Bousquet J, Annesi-Maesano I, Carat F, Léger D, Rugina M, Pribil C, et al. Characteristics of intermittent and persistent allergic rhinitis: DREAMS study group. Clin Exp Allergy. 2005;35:728-32.

8. Soose RJ. Role of allergy in sleep-disordered breathing. Otolaryngol Clin North Am. 2011;44:625-35.

9. Ahmadiafshar A, Farjd HR, Moezzi F, Mousavinasab N. Nasal polyposis in patients with asthma and allergic rhinitis. J Laryngol Otol. 2012;126:780-3.

10. Bousquet J, Khaltaev N, Cruz AA, Denburg J, Fokkens WJ, Togias A, et al. Allergic Rhinitis and its Impact on Asthma (ARIA) 2008 update (in collaboration with the World Health Organization, GA(2)LEN and AllerGen). Allergy. 2008;63 Suppl 86:8-160

11. Smith L, Nguyen T, Seeto C, Saini B, Brown L. The role of non-clinicians in a goal setting model for the management of allergic rhinitis in community pharmacy settings. Patient Educ Couns. 2011;85(2):e26-32.

12. Baiardini I, Braido F, Tarantini F, Porcu A, Bonini S, Bousquet PJ, et al. GA2LEN ARIA-suggested drugs for allergic rhinitis: what impact on quality of life? A GA2LEN review Allergy. 2008;63(6):660-9.

13. Lombardi C, Canonica GW, Passalacqua G. IGRAM, Italian Group on Respiratory Allergy in Migrants. The possible influence of the environment on respiratory allergy: a survey on immigrants to Italy. Ann Allergy Asthma Immunol. 2011;106(5):407-11.

14. Mösges $R$, Klimek $L$. Today's allergic rhinitis patients are different: new factors that may play a role. Allergy. 2007;62:969-75.

15. Valovirta E, Myrseth SE, Palkonen S. The voice of the patients: allergic rhinitis is not a trivial disease Curr Opin Allergy Clin Immunol.2008; 8: 1-9
16. Ernst E. The role of complementary and alternative medicine. Br Med J. 2000;321:1133.

17. Senna G, Passalacqua G, Crivellaro M, Bonadonna P, Gani F, Dorizzi R, et al. Unconventional medicine: a risk of undertreatment of allergic patients. Allergy. 1999;54(10):1117-9.

18. Anonimous. Allergic rhinitis: common, costly and neglected. The Lancet. 2009;371:2057.

19. Smith L, Nguyen T, Seeto C, Saini B, Brown L. The role of non-clinicians in a goal setting model for the management of allergic rhinitis in community pharmacy settings Patient Educ Couns. 2011; 85: e26-32

20. Williams A, Scadding G. Is reliance on self-medication and pharmacy care adequate for rhinitis patients? Int J Clin Pract. 2009;63:98-104.

21. Porteous T, Wyke S, Smith S, Bond C, Francis J, Lee AJ, et al. 'Help for Hay Fever', a goal-focused intervention for people with intermittent allergic rhinitis, delivered in Scottish community pharmacies: study protocol for a pilot cluster randomized controlled trial. Trials. 2013;14:217.

22. Canonica GW, Baena-Cagnani CE, Compalati E, Bohle B, Bonini S, Bousquet J, et al. 100 years of immunotherapy: the Monaco charter. under the high patronage of His Serene Highness Prince Albert II of Monao. Int Arch Allergy Immunol. 2013;160:346-9.

\section{Submit your next manuscript to BioMed Central and take full advantage of:}

- Convenient online submission

- Thorough peer review

- No space constraints or color figure charges

- Immediate publication on acceptance

- Inclusion in PubMed, CAS, Scopus and Google Scholar

- Research which is freely available for redistribution 